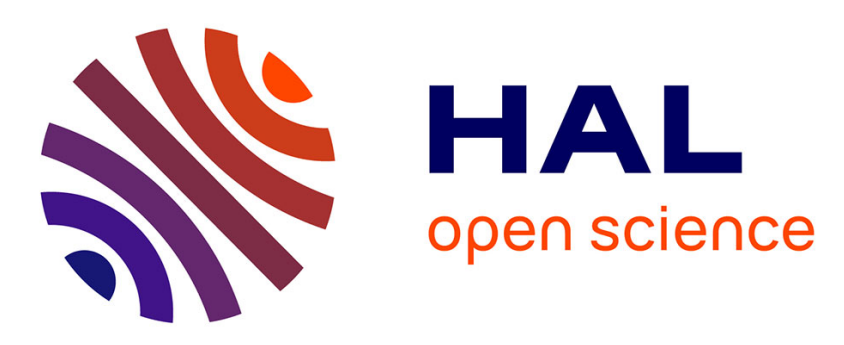

\title{
Preferential Hyperacuity Perimeter in assessing responsiveness to ranibizumab therapy for exudative age-related macular degeneration
}

Giuseppe Querques, Elya Berboucha, Nicolas Leveziel, Alfredo Pece, Eric H Souied

\section{To cite this version:}

Giuseppe Querques, Elya Berboucha, Nicolas Leveziel, Alfredo Pece, Eric H Souied. Preferential Hyperacuity Perimeter in assessing responsiveness to ranibizumab therapy for exudative age-related macular degeneration. British Journal of Ophthalmology, 2010, 95 (7), pp.986. 10.1136/bjo.2010.190942 . hal-00602301

\section{HAL Id: hal-00602301 https://hal.science/hal-00602301}

Submitted on 22 Jun 2011

HAL is a multi-disciplinary open access archive for the deposit and dissemination of scientific research documents, whether they are published or not. The documents may come from teaching and research institutions in France or abroad, or from public or private research centers.
L'archive ouverte pluridisciplinaire HAL, est destinée au dépôt et à la diffusion de documents scientifiques de niveau recherche, publiés ou non, émanant des établissements d'enseignement et de recherche français ou étrangers, des laboratoires publics ou privés. 


\section{- Original Article -}

Preferential Hyperacuity Perimeter in assessing responsiveness to ranibizumab therapy for exudative age-related macular degeneration

Giuseppe Querques, MD, PhD (1) (2), Elya Berboucha, MD (1), Nicolas Leveziel, MD (1), Alfredo Pece, MD (2), Eric H Souied, MD, PhD (1).

(1) Department of Ophthalmology, University of Paris XII, Centre Hospitalier Intercommunal de Creteil, Creteil, France.

(2) Retina 3000 Foundation ONLUS, Milan, Italy.

Correspondence request to:

Dr Giuseppe Querques, Department of Ophthalmology, University of Paris XII, Centre Hospitalier Intercommunal de Creteil, 40 Avenue de Verdun, 94000 Creteil, France.

Telephone: +33(0)1451752 22

Fax: +33 (0)145175266

E mail: giuseppe.querques@hotmail.it. 
Word count for text: 2714.

Word count for references: 397.

Short title: PHP in exudative AMD

This study was supported thorough a research fellowship by the Retina 3000 Foundation.

The authors have no proprietary interest in the materials used in this study.

No author has any conflict of interest.

Competing Interest: None declared.

Keywords: Age-related macular degeneration; choroidal neovascularization; metamorphopsia; optical coherence tomography; preferential hyperacuity perimeter; ranibizumab. 


\section{Abstract}

Background: To investigate the ability of Preferential Hyperacuity Perimeter in assessing responsiveness to ranibizumab therapy for exudative age-related macular degeneration (AMD).

Methods: Fourteen consecutive patients with newly diagnosed choroidal neovasularization underwent Preferential Hyperacuity Perimeter metamorphopsia test (main outcome measures), 1 hour before (baseline) and 1 hour, 1 day, 1 week and 1 month after one intravitreal injection of ranibizumab $(0.05 \mathrm{ml} / 0.5 \mathrm{mg})$. Best-corrected visual acuity (BCVA), and several spectral domain optical coherence tomography (OCT) parameters (secondary outcome measures) were compared to metamorphopsia test.

Results: Fourteen eyes (14 patients, $78 \%$ women, mean age $83 \pm 6.2$ years) were included in the analysis. Mean Preferential Hyperacuity Perimeter metamorphopsia test score significantly improved from $20.4 \pm 35$ to $9.2 \pm 23$, after the single ranibizumab injection $(p<0.05)$. Mean reduction in central macular thickness, maximal retinal thickness at the fovea, maximal height of subretinal fluid, maximal diameter of the largest retinal cyst and maximal height of pigment epithelial detachment, as evaluated by spectral domain OCT, well reflected the functional improvements as evaluated by Preferential Hyperacuity Perimeter, showing a significant correlation with metamorphopsia changes (0.9 Spearman correlation, $p<0.05)$. Mean BCVA also significantly improved from $20 / 80$ to $20 / 60(p<0.05)$. A significant correlation was also found between the mean BCVA changes and the mean metamorphopsia changes (0.97 Spearman correlation, $\mathrm{p}<0.05)$. The correlation coefficient between OCT measurements and PHP score within subjects was $0.51(p<0.05)$

Conclusion: The improvement in metamorphopsia test score after intravitreal ranibizumab injection, which well correlates with improvement in several OCT parameters, 
suggests that Preferential Hyperacuity Perimeter may be used to monitor response to antiVEGF treatment in patients with exudative AMD. 


\section{Introduction}

Visual acuity, the most widely diffuse measure of visual function, has shown poor degree of correlation with both qualitative (fluorescein angiography) and quantitative (optical coherence tomography [OCT]) assessments of macular morphology ${ }^{1-3}$. Also other less commonly used measures of function, such as contrast sensitivity, microperimetry, near acuity and reading speed, did not show better relationships with morphological features compared with visual acuity ${ }^{4-7}$. Therefore, to date, there are still no simple and reproducible functional tests that reflect the morphological state of the macula in patients affected with diseases like exudative age-related macular degeneration (AMD).

The Prospective OCT Imaging of Patients with Neovascular AMD Treated with intraOcular Ranibizumab (PrONTO) Study ${ }^{8}$ showed that monthly visits, for both functional and morphological monitoring, are necessary in patients undergoing intravitreal anti-VEGF treatment for $\mathrm{AMD}$, in order to take optimal re-treatment decisions ${ }^{9}$. However, based on clinical experience, it seems that in such patients, visual acuity changes would lag behind morphological worsening. Therefore, availability of an objective and easily performed functional test, which well correlates with macular morphology, would be extremely helpful in the clinic setting.

Preferential Hyperacuity Perimetry (Foresee PHP®, Notal Vision, Israel) has recently gained popularity as a device for monitoring visual distortion, and has been used to localize functional deficits in the central 14 degrees of visual field in patients with $A M D^{10,11}$. Since 2005 Preferential Hyperacuity Perimeter has been proposed as a tool to detect $\mathrm{CNV}^{10}$. Results of a multicenter clinical trial confirmed the usefulness of Preferential Hyperacuity Perimeter for detection of $A M D^{11}$. Recently, the home version of the Preferential Hyperacuity Perimeter, the ForeseeHome, which is based on a technology that is similar to the Foresee PHP, has shown a good sensitivity and specificity in 
discriminating between patients with newly diagnosed CNV and intermediate $\mathrm{AMD}^{12}$. Preferential Hyperacuity Perimeter has also been suggested as a tool for monitoring the therapeutic response to photodynamic therapy and anti-VEGF treatment in neovascular $\mathrm{AMD}^{13,14}$.

In this pilot study we investigated the ability of Foresee Preferential Hyperacuity Perimetry (PHP) in assessing responsiveness to ranibizumab therapy. With this aim, we analyzed the short-term functional and morphological fluctuations after intraviteal ranibizumab injection for exudative AMD.

\section{Methods}

Fourteen consecutive patients with exudative AMD in one eye received an intravitreal injection of ranibizumab $(0.05 \mathrm{ml} / 0.5 \mathrm{mg})$ at the University Eye Clinic of Creteil. In this prospective pilot study, we investigated the ability of PHP in assessing responsiveness to ranibizumab therapy. Before administration of ranibizumab, patients were informed about the experimental aspects of the study and the need for repeating several examinations at each scheduled follow-up visit. Criteria for inclusion were: 1) age $\geq 50$ years old, 2) bestcorrected visual acuity (BCVA) between 20/200 and 20/40 as evaluated by Early Treatment Diabetic Retinopathy Study (ETDRS) charts, 3) presence of newly diagnosed subfoveal CNV secondary to AMD showing at least $50 \%$ active lesion as evaluated by fundus biomicroscopy, fluorescein angiography (FA) and infracyanine green angiography (ICGA), 4) subretinal fluid, cystic maculopathy, or 1-mm central macular thickness of at least $250 \mu \mathrm{m}$ on OCT. Patients with previous treatment for exudative AMD in the study eye, previous surgery in the study eye in the last 6 months before intravitreal injection of ranibizumab (potentially influencing the macular status), refractive error of more than -6 
diopters, CNV attributable to other causes than AMD, active intraocular inflammation or any other retinopathy (such as diabetic retinopathy, retinal venous occlusion or epiretinal membrane) in the study eye, were excluded.

Foresee PHP was performed 1 hour before the treatment (baseline) under the supervision of a trained physician (GQ). During the test, the patient's visual attention is drawn to a fixation cue displayed at the center of a touch screen. When the device automatically recognizes that the patient is ready to respond, a stimulus is briefly presented on the display. Each stimulus consists of a dotted line, of which a few dots are misaligned relative to the main axis of the stimulus. If the degree of misalignment exceeds a personal threshold, the patient may perceive an artificial distortion. The patient's task is to identify where the distortion appears, and to mark this location on the display. A succession of such stimuli is flashed on various locations of the display, such as to cover the entire macular field. When a stimulus is flashed on a location that corresponds to a healthy portion of the retina, the artificial distortion is readily detected. If the stimulus is flashed on a location that corresponds to a CNV lesion, RPE elevation may create the perception of a pathological distortion. In the patient's perception, competition for visual attention takes place between the artificial and pathological distortions. If the pathological distortion is more prominent than the artificial distortion, the patient is more likely to perceive the former and ignore the latter. During the test, varying sizes of artificial distortions are displayed, allowing quantification of the degree of the pathological distortion. A compilation of the errors performed during the test enables location of the visual distortions as well as estimation of their severity. For severity measurements we have used the "PHP test score" (a continuous, global score, between -30 and +600 ).

One hour before performing intravitreal ranibizumab injection, each patient also underwent a baseline assessment of BCVA measured at $4 \mathrm{~m}$ with standard ETDRS charts, and a 
complete ophthalmic examination that included slit-lamp biomicroscopy, intraocular pressure measurement and spectral domain OCT utilizing the Spectralis Heidelberg Retinal Angiograph OCT (Spectralis HRA-OCT Heidelberg Engineering, Heidelberg, Germany). In this study we used, at each follow-up visit, the "follow-up" protocol of Spectralis HRA-OCT, which grants reacquisition of each OCT line actually referenced with the baseline acquisition.

The retinal thickness of the $1-\mathrm{mm}$ central retina (central macular thickness) was evaluated using a 19 horizontal lines protocol. Several OCT parameters, reflecting the disease activity, were also evaluated on a single (for each eye) spectral domain OCT scan. For selection, scans had to show the lesion and the presumed fovea. Parameters measured in the selected scan included: maximal retinal thickness at the fovea, maximal height of subretinal fluid, maximal diameter of the largest retinal cyst and maximal height of pigment epithelium detachment.

PHP test (performed under the supervision of a trained physician [GQ]), as well as assessment of BCVA measured at $4 \mathrm{~m}$ with standard ETDRS charts, and Spectralis HRAOCT utilizing the "follow-up" protocol, were performed 1 hour, 1 day, 1 week and 1 month after the intravitreal injection of ranibizumab.

Descriptive statistics were performed to present, by graphs, the trends of change for the different features (BCVA converted to the logarithm of the minimum angle of resolution [LogMAR], the OCT parameters investigated [central macular thickness, maximal retinal thickness at the fovea, maximal height of subretinal fluid, maximal diameter of the largest retinal cyst and maximal height of pigment epithelium detachment], the "combined parameter" [sum the last former four parameters] and PHP measurements represented as "test score" (Test score = log [Probability(Responses pattern\CNV) / Probability(Responses pattern\Intermediate)]). 
Since the normality assumption was not satisfied for the measurement variables, we have used nonparametric tests: the Spearman correlation was evaluated, in order to examine the degree of correlation between OCT average parameters change, LogMAR BCVA average change and PHP test score average change. Differences between baseline and 1 month visits were compared using Wilcoxon signed rank test.

For the question of whether an increase in PHP test score within the individual was associated with an increase in OCT combined parameter, we had removed the differences between subjects and look only at changes within by multiple regression method, using the OCT data as the outcome variable and the PHP test score and the subject as the predictor variables. Subject is treated as a categorical factor using dummy variables ${ }^{(15)}$. In order to investigate the relative change vs baseline examination, all parameters were collected to a table and classified as "better", "worse" or "same" with respect to BCVA (LogMAR change $>0.1$ ), "combined OCT parameter" (change $>10$ microns) and PHP test score (change $>15$ ).

An analysis of variance for repeated measures (ANOVA) was performed in order to determine the effect of time on the different measurements. The chosen level of statistical significance was $p<0.05$.

\section{Results}

Fourteen treatment naive eyes of 14 consecutive Patients with exudative AMD met the inclusion criteria and were included in the analysis. Demographic and clinical data for these patients are summarized in table 1 . The mean age was $83 \pm 6.2$ years, and the gender distribution was $78 \%$ women. All included patients presented at each scheduled follow-up visit, and underwent all examinations except for 3 patients who missed the PHP examination at the last follow-up visit (1 month after the intravitreal ranibizumab injection). 
Therefore, 67 out of the 70 scheduled PHP tests were performed at 1 month. All PHP tests made in this study except $3(4 \%)$ showed a good a reliability score.

In table 2 are summarized the functional changes (as evaluated by PHP metamorphopsia test score and BCVA) and the morphological changes (as evaluated by Spectralis spectral domain OCT, "follow-up protocol") within the first month from intravitreal ranibizumab injection. Mean baseline PHP metamorphopsia test score was $20.4 \pm 35$, and there was a significant improvement to $9.2 \pm 23$, at 1 month (Wilcoxon signed rank test, $p<0.05$ ). Mean baseline BCVA was 0.6 LogMAR (20/80), and there was a significant improvement to 0.5 LogMAR (20/60), at 1 month (Wilcoxon signed rank test, $p<0.05)$.

The mean baseline central macular thickness was $413 \pm 142 \mu \mathrm{m}$. It significantly reduced to $303 \pm 58 \mu \mathrm{m}$ at 1 month (Wilcoxon signed rank test, $p<0.05$ ). Mean reduction in "combined OCT parameter" (central macular thickness, maximal retinal thickness at the fovea, maximal height of subretinal fluid, maximal diameter of the largest retinal cyst and maximal height of pigment epithelium detachment) was also recorded at 1 month (Wilcoxon signed rank test, $\mathrm{p}<0.05$ ).

The natural dynamics, both anatomical and functional, within the first month following intravitreal ranibizumab injection are presented in table 2 and figure 1 (case presentation). It is notable that there was an improvement in all parameters, and that for BCVA and OCT the majority of significant changes happened within 1 day to 1 week after treatment $(p<0.05)$. Interestingly, there was an increase in the metamorphopsia score one hour after the injection. The formal analysis and the quantification of the relationships between functional and morphological changes are presented in figures 2-4. There was a significant correlation between the PHP metamorphopsia changes and the OCT anatomical changes (0.81 Spearman correlation, $p<0.05)$. A significant correlation was found between the PHP metamorphopsia changes and the mean BCVA changes (0.95 Spearman correlation, 
$p<0.05)$. There was also a significant correlation between the mean BCVA changes and the OCT anatomical changes $(0.95$ Spearman correlation, $p<0.05)$.

The correlation coefficient between OCT measurements and PHP score within subjects was $0.51(p<0.05)$ (which indicates that an increase in OCT combined parameter was associated with an increase in PHP test score within the individual).

An analysis of variance for repeated measures (ANOVA) showed a negative significant impact of treatment (improvement over time) on BCVA logMAR, OCT combined parameter, and PHP test score (Type III tests of fixed effects, $p<0.05$ ). The time points with the highest impact on the model were 1 week and 1 month after treatment for both BCVA and OCT, and the 1 week time point for the PHP ( $<<0.05$ for these time points).

Categorized functional and morphological changes ("better", "worse" or "same"), for each eye, at each time-point relative to baseline, are reported in table 3.

\section{Discussion}

In this prospective study we investigated the ability of Foresee PHP in assessing responsiveness to intravitreal ranibizumab injection, in 14 consecutive patients affected with newly diagnosed exudative AMD. After a single intravitreal ranibizumab injection, we found mean PHP metamorphopsia test score significantly improved from $20.4 \pm 35$ to 9.2 \pm 23 . Moreover, in order to test if PHP functional measures correlate with macular morphology measures, we also investigated the significance of correlation existing between PHP test score, and several OCT parameters, during the duration of the study. Interestingly, the functional improvements as evaluated by PHP well reflected the mean reduction in all OCT parameters (central macular thickness, maximal retinal thickness at the fovea, maximal height of subretinal fluid, maximal diameter of the largest retinal cyst 
and maximal height of pigment epithelium detachment) showing a significant correlation with metamorphopsia changes (0.81 Spearman correlation, $\mathrm{p}<0.05)$.

In our series, also mean BCVA significantly improved from $20 / 80$ to $20 / 60$, after the single intravitreal ranibizumab injection, and a significant correlation was found between BCVA changes and the PHP metamorphopsia changes (2 different functional measures) during the duration of the study (0.95 Pearson correlation, $\mathrm{p}<0.05)$.

It is noteworthy that both a significant functional (PHP and BCVA), and morphological improvement (OCT parameters) were recorded as soon as 1 day after the intravitreal ranibizumab injection. The exceptional increase in the metamorphopsia score one hour after the injection, may be attribute to the emotional state and maybe some local disturbances due to the injection, which, all may affect a psychophysical test.

Das et $\mathrm{al}^{14}$ have recently published a retrospective analysis (lacking of a standardized interval between treatment and reexamination) of usually collected clinical data (BCVA and OCT) and PHP from patients undergoing treatment with ranibizumab. The authors found that changes in PHP distortion maps did not correlate with maximal retinal thickness, and with BCVA (a total of 34 BCVA- PHP tests-retests). Also, BCVA changes (less than half of one ETDRS line) did not correlate with OCT changes. However, it is worth noting that the authors did not set out to specifically test whether PHP could help with assessing responsiveness to ranibizumab therapy. Conversely, in the current study, we included only treatment naive eyes, which were regularly followed (prospectively) and re-examined at several fixed time-points (67 BCVA-PHP tests-retests), during a limited 1month period.

The strong correlation here reported between functional PHP metamorphopsia changes and morphological OCT changes is even more important considering the population 
included in this study: patients with exudative AMD undergoing intravitreal anti-VEGF injections. Given that there is universal acceptance amongst clinicians that monthly visits, for both functional and morphological monitoring, are necessary in patients undergoing intravitreal anti-VEGF treatment for AMD, the availability of an objective and easily performed functional test (as the PHP), which correlates well with macular morphology, would be extremely helpful in the clinic setting, in order to take optimal re-treatment decisions. For this reason, a home version of the PHP, the ForeseeHome, is currently under development. The ForeseeHome is based on a technology that is similar to the Foresee PHP. This home-based test has been designed for self-monitoring AMD patients (Loewenstein A. Poster presented at: AAO Annual Meeting, November 8-11 2008; Atlanta). As with Foresee PHP, the ForeseeHome seems to be superior to the Amsler grid in terms of accuracy of CNV detection (Loewenstein A. Poster presented at ASRS Annual Meeting, October 10-15 2008; Maui) ${ }^{12}$. It is expected that the test will serve as a followup tool for patients to self-test with the ForeseeHome on a frequent basis ${ }^{12}$.

Our study has several limitations. All patients underwent a single injection of ranibizumab. The sample size was small, and 3 patients missed the PHP examination at 1 month; also, despite 67 PHP tests were performed over 1 month, follow-up is short, and no definitive conclusion can be drawn. In addition, even though we found a significant correlation between progressive reduction of morphological signs of disease activity (OCT parameters), and functional improvements as evaluated by PHP, this applied to newly diagnosed active CNVs; therefore, we actually have no data on such a correlation, in eyes with CNV evolving towards quiescent inactive fibro-atrophic lesions, as it may happen following a certain number of repeated anti-VEGF treatments. Finally, we did not perform other tests (such as NEI VFQ -25 and microperimetry), which would have been useful to 
better characterize the short-term functional and morphological fluctuations in these patients.

In conclusion, we found that functional improvement in metamorphopsia test score after intravitreal ranibizumab injection, well correlates with improvement in several OCT parameters reflecting the disease activity. Our findings suggest that PHP may be considered an useful tool to monitor response to anti-VEGF treatment in patients with exudative AMD. Further studies are needed to establish the sensibility of PHP compared with other functional and morphological measurements in the detection of recurrences in patients undergoing anti-VEGF treatment for exudative AMD. 


\section{References}

1.Doris N, Hart PM, McCleland J, et al. Relation between macular morphology and visual function in patients with choroidal neovascularisation of age-related macular degeneration. Br J Ophthalmol 2001;85:184-188.

2. Hogg R, Stevenson MR, Winder J, et al. Macular lesion composition and location influence visual function in AMD. Br J Ophthalmol 2003; 87:609-614.

3. Querques G, Bux AV, Prato R, et al. Correlation of visual function impairment and optical coherence tomography findings in patients with adult-onset foveomacular vitelliform macular dystrophy. Am J Ophthalmol 2008;146:135-142.

4. McClure M, Hart PM, Stevenson MR, et al. Correlations between visual function and performance of daily living tasks. Br J Ophthalmol 2000;84:244-250.

5. Mitchell J, Wolffsohn J, Woodcock A, et al. The MacDQoL Individualized Measure of the Impact of Macular Degeneration on Quality of Life: Reliability and Responsiveness Am J Ophthalmol 2008;146:447-454.

6. Moutray T, Alarbi M, Mahon G, et al. Relationships between clinical measures of visual function, fluorescein angiographic and optical coherence tomography features in patients with subfoveal choroidal neovascularisation. $\mathrm{Br} \mathrm{J}$ Ophthalmol 2008;92:361-364.

7. Browning DJ, Glassman AR, Aiello LP, et al. Relationship between optical coherence tomography-measured central retinal thickness and visual acuity in diabetic macular edema. Ophthalmology 2007;114:525-536.

8. Lalwani GA, Rosenfeld PJ, Fung AE, et al. A variable-dosing regimen with intravitreal ranibizumab for neovascular age-related macular degeneration: year 2 of the PrONTO Study. Am J Ophthalmol 2009;148:43-58. 
9. Querques G, Azrya S, Martinelli D, et al. Ranibizumab for exudative age-related macular degeneration: 24-month outcomes from a single-centre institutional setting.

Br J Ophthalmol 2010;94:292-296.

10. Alster Y, Bressler NM, Bressler SB, et al. Preferential Hyperacuity Perimeter (PreView PHP) for detecting choroidal neovascularization study. Ophthalmology 2005;112:17581765

11. Goldstein M, Loewenstein A, Barak A, et al. Results of a multicenter clinical trial to evaluate the preferential hyperacuity perimeter for detection of agerelated macular degeneration. Retina 2005;25:296-303.

12. Loewenstein A, Ferencz J, Lang Y, et al. Toward earlier detection of choroidal neovascularization secondary to age-related macular degeneration: multicenter evaluation of a preferential hyperacuity perimeter designed as a home device. Retina 2010;30:10581064.

13. Trevino R. Recent progress in macular function self assessment. Ophthalmic Physiol Optics 2008;28:183-192.

14. Das R, Shi Y, Silvestri G, et al. Distortion maps from preferential hyperacuity perimetry are helpful in monitoring functional response to Lucentis therapy. Retina 2009;29:10131018.

15. Bland JM, Altman DG, Statistics notes: Calculating correlation coefficients with repeated observations: Part 1—correlation within subjects. BMJ 1995;310:446. 


\section{Legends}

Figure 1. Example of functional and morphological fluctuation, as evaluated by Preferential Hyperacuity Perimetry (top panel) and spectral domain optical coherence tomography (central transverse section of the macula [top panel], and transverse section where the pigment epithelium detachment is most prominent [bottom panel]), from baseline (1 hour before, A), to 1 hour (B), 1 day (C), 1 week (D), and 1 month (E) after intravitreal ranibizumab injection for exudative age-related macular degeneration. Fluorescein angiography shows late leakage from the coroidal neovascularization before the intravitreal ranibizumab injection ( $A$, top panel, small square).

Figure 2. Relationship between spectral domain optical coherence tomography (SD OCT) and Preferential Hyperacuity Perimetry (PHP) during one month following intravitreal ranibizumab injection for exudative age-related macular degeneration.

Combined SD OCT parameters (maximal retinal thickness at the fovea, maximal height of subretinal fluid, maximal diameter of the largest retinal cyst and maximal height of pigment epithelium detachment) $(\mu \mathrm{m})$ and PHP test score, from baseline until one month after a single intravitreal ranibizumab injection. The correlation between the OCT morphological changes and the Preferential Hyperacuity Perimetry functional changes is 0.81 (Spearman correlation, $\mathrm{P}<0.05)$.

Figure 3. Relationship between best-corrected visual acuity (BCVA) and Preferential Hyperacuity Perimetry (PHP) during one month following intravitreal ranibizumab injection for exudative age-related macular degeneration. 
VA (LogMAR) and PHP test score, from baseline until one month after a single intravitreal ranibizumab injection. The correlation between the BCVA changes and the Preferential Hyperacuity Perimetry functional changes is 0.95 (Spearman correlation, $\mathrm{P}<0.05$ ).

Figure 4. Relationship between spectral domain optical coherence tomography (SD OCT) and best-corrected visual acuity (BCVA) during one month following intravitreal ranibizumab injection for exudative age-related macular degeneration.

Combined spectral domain OCT parameters (maximal retinal thickness at the fovea, maximal height of subretinal fluid, maximal diameter of the largest retinal cyst and maximal height of pigment epithelium detachment) ( $\mu \mathrm{m})$ and VA (LogMAR), from baseline until one month after a single intravitreal ranibizumab injection. The correlation between the OCT morphological changes and BCVA is 0.95 (Spearman correlation, $\mathrm{P}<0.05$ ). 


\section{Acknowledgements}

This study was supported thorough a research fellowship by the Retina 3000 Foundation.

The principal investigator had full access to all the data in the study and takes responsibility for the integrity of the data and the accuracy of the data analysis.

"The Corresponding Author has the right to grant on behalf of all authors and does grant on behalf of all authors, an exclusive licence (or non-exclusive for government employees) on a worldwide basis to the BMJ Publishing Group Ltd, and its Licensees to permit this article (if accepted) to be published in British Journal of Ophthalmology and any other BMJPGL products and to exploit all subsidiary rights, as set out in our licence (http://group.bmj.com/products/journals/instructions-for-authors/licence-forms)."

Giuseppe Querques: Competing Interest: None declared.

Elya Berboucha: Competing Interest: None declared.

Nicolas Leveziel: Competing Interest: None declared.

Alfredo Pece: Competing Interest: None declared.

Eric H Souied: Competing Interest: None declared. 
Table 1. Demographic and clinical data of patients treated by intravitreal ranibizumab injection for exudative macular degeneration.

\begin{tabular}{lllll}
\hline Patient (eye)\# & GENDER & AGE & EYE & CNV SUBTYPE \\
& & & & \\
\hline 1 & M & 89 & LE & Occult \\
2 & F & 81 & RE & Predominantly Classic \\
3 & F & 74 & RE & Retinal Angiomatous Proliferation \\
4 & F & 74 & LE & Occul \\
5 & F & 84 & RE & Minimally Classic \\
6 & F & 89 & LE & Minimally Classic \\
7 & F & 84 & LE & Occul \\
8 & F & 82 & RE & Occul \\
9 & F & 76 & LE & Occul \\
10 & F & 81 & RE & Occul \\
11 & M & 77 & LE & Occul \\
12 & F & 96 & LE & Occul \\
13 & M & 80 & RE & Occul \\
\hline 14 & 86 & RE & Occul \\
\hline
\end{tabular}

M: male; F: female; RE: right eye; LE: left eye; CNV: choroidal neovasularization. 
PHP fluctuation in exudative AMD

Table 2. Functional and morphological characteristics of patients with exudative macular degeneration, at baseline ( 1 hour befo re intravitral ranibizumab injection), and 1 hour, 1 day, 1 week and 1 month after intravitral ranibizumab injection.

\begin{tabular}{|c|c|c|c|c|c|c|c|c|}
\hline & $\begin{array}{l}\text { Mean BCVA } \\
\text { (LogMAR) }\end{array}$ & $\begin{array}{l}\text { PHP } \\
\text { Test Score }\end{array}$ & Mean CMT & $\begin{array}{l}\text { Mean } \\
\text { MHSRF }\end{array}$ & Mean MRTF & $\begin{array}{l}\text { Mean } \\
\text { MHPED }\end{array}$ & Mean MDRC & $\begin{array}{l}\text { Combined } \\
\text { OCT } \\
\text { parameters } \\
\text { (Mean) }\end{array}$ \\
\hline Baseline & $0.6 \pm 0.3$ & $20.4 \pm 35$ & $413 \pm 142 \mu \mathrm{m}$ & $79 \pm 93 \mu \mathrm{m}$ & $384 \pm 109 \mu \mathrm{m}$ & $192 \pm 137 \mu \mathrm{m}$ & $102 \pm 151 \mu \mathrm{m}$ & $757 \pm 298 \mu \mathrm{m}$ \\
\hline 1 hour & $0.6 \pm 0.3$ & $24 \pm 33$ & $410 \pm 142 \mu \mathrm{m}$ & $77 \pm 91 \mu \mathrm{m}$ & $381 \pm 108 \mu \mathrm{m}$ & $192 \pm 136 \mu \mathrm{m}$ & $102 \pm 151 \mu \mathrm{m}$ & $752 \pm 296 \mu \mathrm{m}$ \\
\hline 1 day & $0.59 \pm 0.34$ & $13 \pm 23$ & $393 \pm 149 \mu \mathrm{m}$ & $66 \pm 89 \mu \mathrm{m}$ & $357 \pm 101 \mu \mathrm{m}$ & $178 \pm 138 \mu \mathrm{m}$ & $73 \pm 142 \mu \mathrm{m}$ & $675 \pm 258 \mu \mathrm{m}$ \\
\hline 1 week & $0.52 \pm 0.32$ & $12.7 \pm 21$ & $318 \pm 65 \mu \mathrm{m}$ & $21 \pm 63 \mu \mathrm{m}$ & $318 \pm 85 \mu \mathrm{m}$ & $152 \pm 85 \mu \mathrm{m}$ & $20 \pm 43 \mu \mathrm{m}$ & $511 \pm 128 \mu \mathrm{m}$ \\
\hline 1 month & $0.5 \pm 0.32$ & $9.2 \pm 23 *$ & $303 \pm 58 \mu \mathrm{m}$ & $4 \pm 13 \mu \mathrm{m}$ & $297 \pm 79 \mu \mathrm{m}$ & $134 \pm 66 \mu \mathrm{m}$ & $15 \pm 39 \mu \mathrm{m}$ & $448 \pm 107 \mu \mathrm{m}$ \\
\hline
\end{tabular}

BCVA: best corrected visual acuity - logarithm of the minimum angle of resolution (LogMAR); CMT: central macular thickness; HSR F: maximal height of subretinal fluid; MRTF: maximal retinal thickness at the fovea; HPED maximal height of pigment epithelium detachment; MDRC: max imal diameter of the largest retinal cyst; combined optical coherence tomography (OCT) parameters investigated (CMT, SRTF, MRTF, HPED, MDRC); Prefer ential Hyperacuity Perimetry (PHP) test score. 
Table 3. Categorized changes, for each eye, at each time-point relative to baseline.

\begin{tabular}{|c|c|c|c|c|c|c|c|c|c|c|c|c|}
\hline \multirow[b]{2}{*}{$\begin{array}{l}\text { Patient } \\
\#\end{array}$} & \multicolumn{3}{|c|}{1 hour after injection } & \multicolumn{3}{|c|}{1 day after injection } & \multicolumn{3}{|c|}{1 week after injection } & \multicolumn{3}{|c|}{1 month after injection } \\
\hline & $\begin{array}{l}\text { LogMAR } \\
B C V A\end{array}$ & $\begin{array}{l}\text { Combined } \\
\text { OCT } \\
\text { parameters }\end{array}$ & $\begin{array}{l}\text { PHP Test } \\
\text { Score }\end{array}$ & $\begin{array}{l}\log M A R \\
B C V A\end{array}$ & $\begin{array}{l}\text { Combined } \\
\text { OCT } \\
\text { parameters }\end{array}$ & $\begin{array}{l}\text { PHP Test } \\
\text { Score }\end{array}$ & $\begin{array}{l}\text { LogMAR } \\
B C V A\end{array}$ & $\begin{array}{l}\text { Combined } \\
\text { OCT } \\
\text { parameters }\end{array}$ & $\begin{array}{l}\text { PHP Test } \\
\text { Score }\end{array}$ & $\begin{array}{l}\text { LogMAR } \\
B C V A\end{array}$ & $\begin{array}{l}\text { Combined } \\
\text { OCT } \\
\text { parameters }\end{array}$ & $\begin{array}{l}\text { PHP Test } \\
\text { Score }\end{array}$ \\
\hline 1 & same & same & worse & same & better & same & same & better & same & same & better & same \\
\hline 2 & same & same & same & same & same & same & same & better & better & same & better & \\
\hline 3 & same & same & same & better & same & same & better & better & same & better & better & same \\
\hline 4 & same & same & same & same & better & same & better & better & same & better & better & same \\
\hline 5 & same & same & better & same & better & same & better & better & better & better & better & better \\
\hline 6 & same & same & same & same & better & worse & same & better & same & same & better & same \\
\hline 7 & same & same & worse & same & same & same & same & same & same & same & same & \\
\hline 8 & same & better & better & same & better & better & same & better & better & same & better & better \\
\hline 9 & same & better & same & same & better & better & same & better & better & better & better & better \\
\hline 10 & same & same & same & same & better & same & same & better & same & same & better & \\
\hline 11 & same & same & same & same & better & same & same & better & same & same & better & same \\
\hline 12 & same & same & same & same & better & same & better & better & same & better & better & same \\
\hline 13 & same & same & same & same & better & same & same & better & same & same & better & better \\
\hline 14 & same & same & worse & same & better & same & same & better & worse & same & better & same \\
\hline
\end{tabular}

BCVA: best corrected visual acuity - logarithm of the minimum angle of resolution (LogMAR); Combined optical coherence tomograp hy (OCT) parameters (central macular thickness; maximal height of subretinal fluid; maximal retinal thickness at the fovea; maximal height of pigment epithelium detachment; maximal diameter of the largest retinal cyst); Preferential Hyperacuity Perimetry (PHP) test score. 


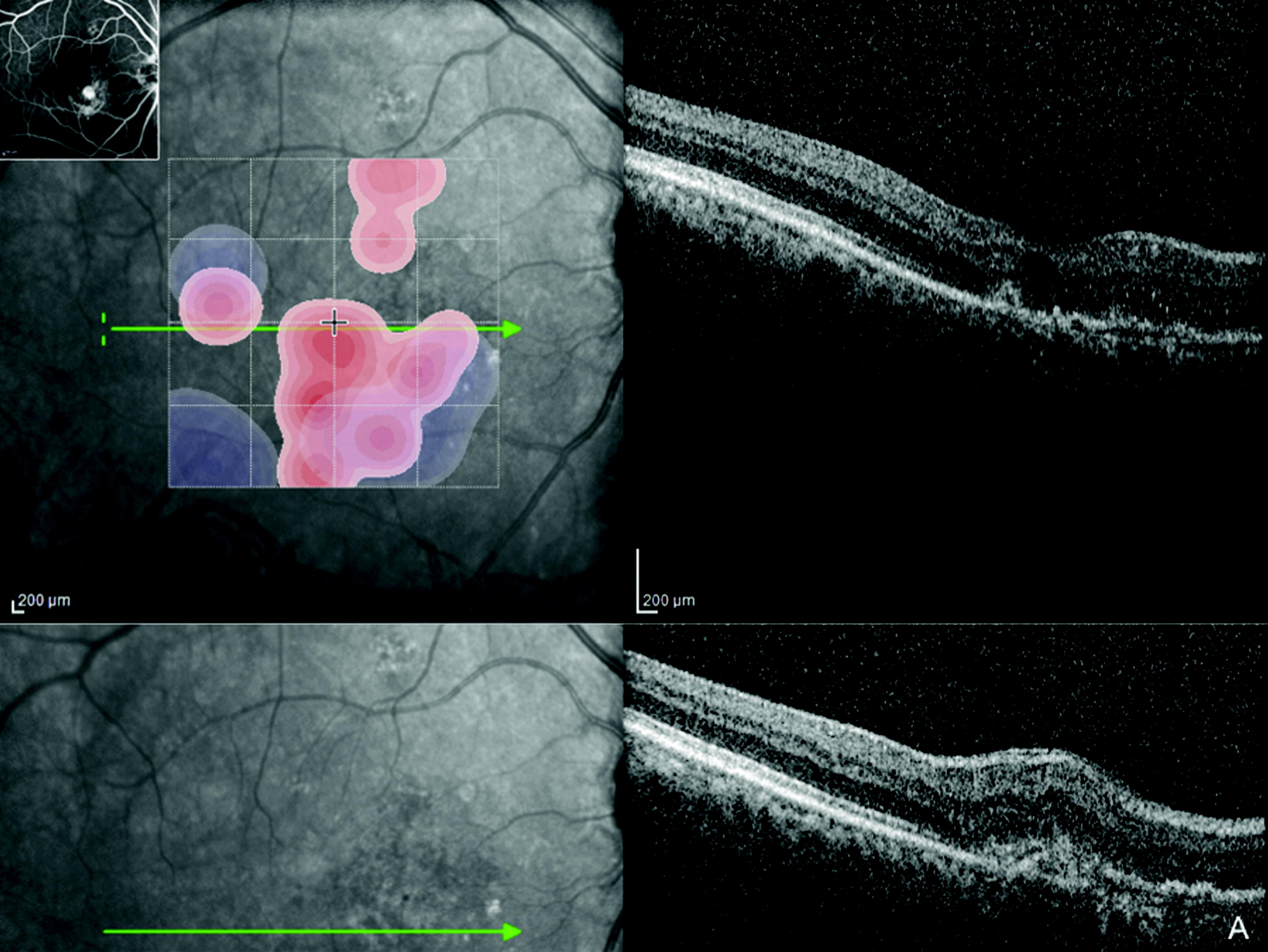




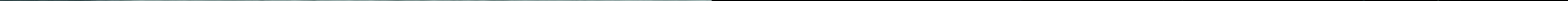



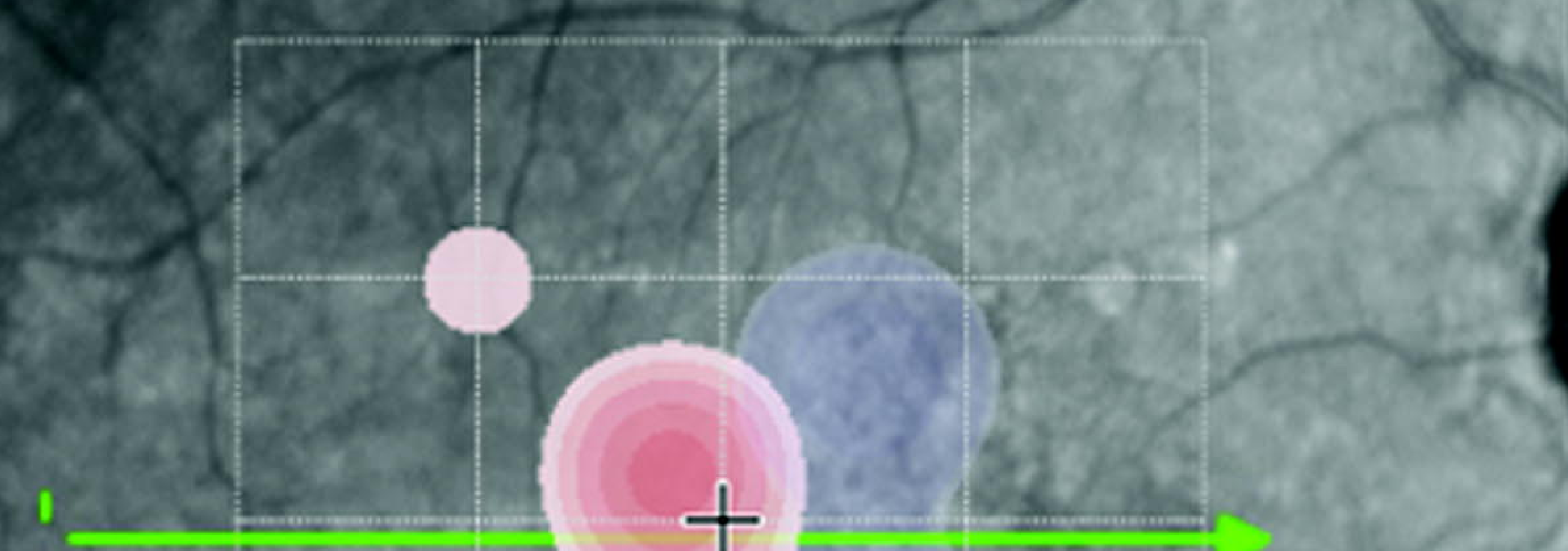

52 3.

$200 \mu \mathrm{m}$ if 4.2

\section{(1)}

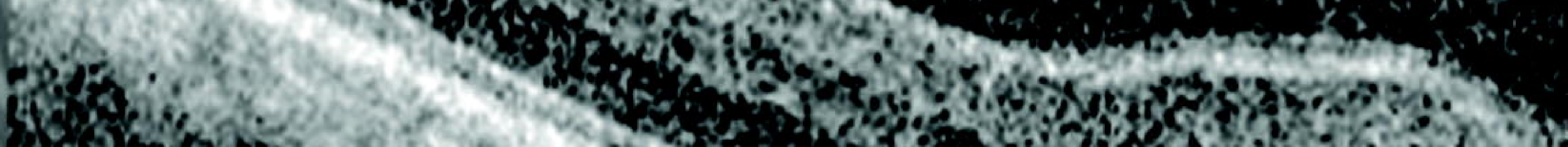
2. , s.

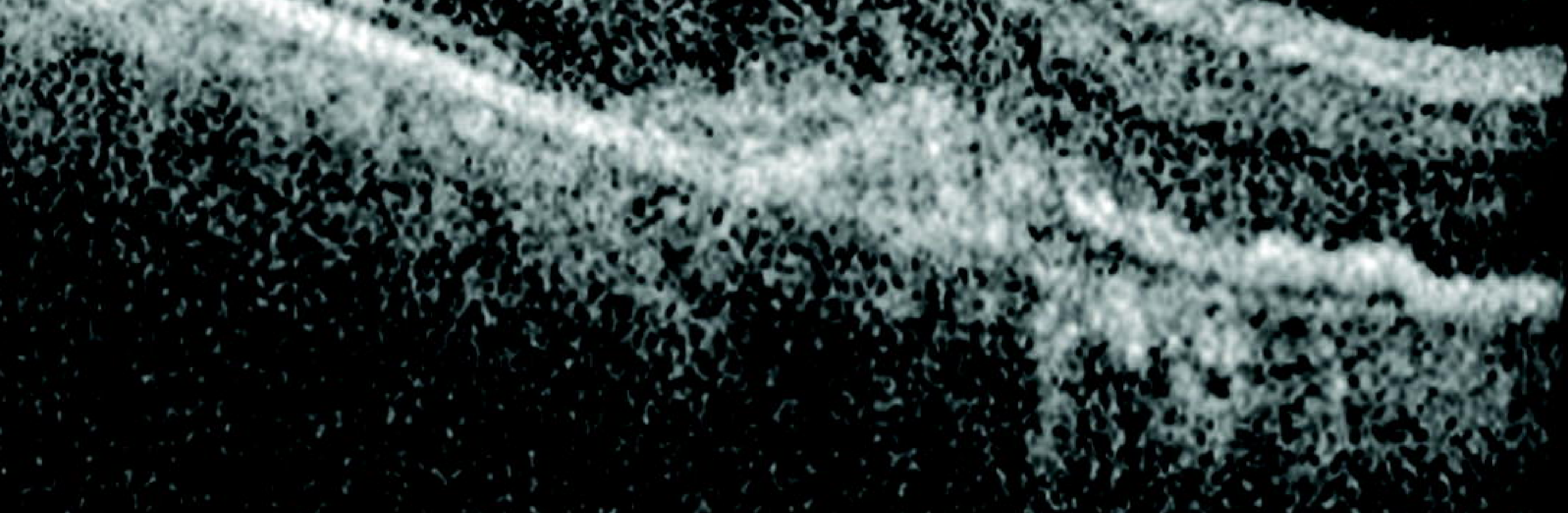


(4)

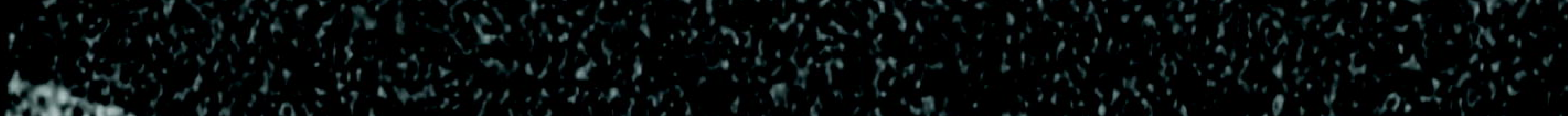

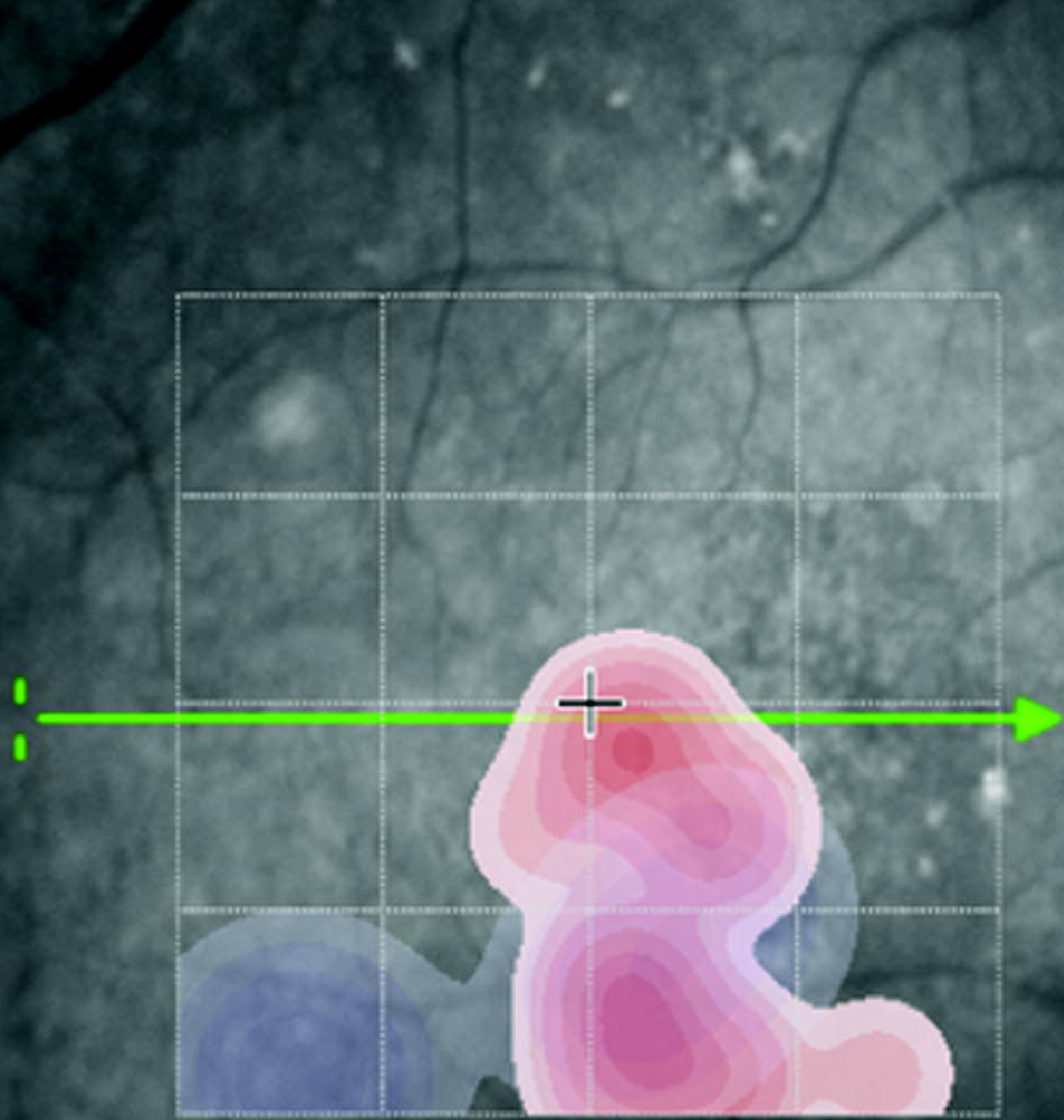

(20) ond

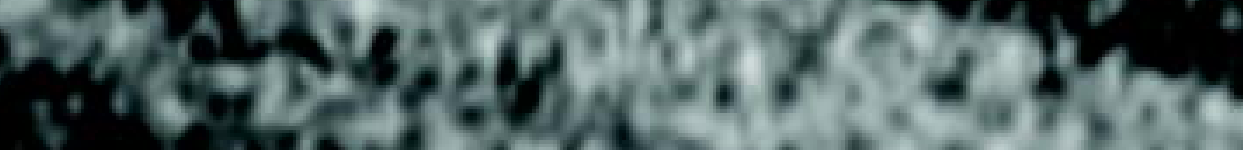

bored

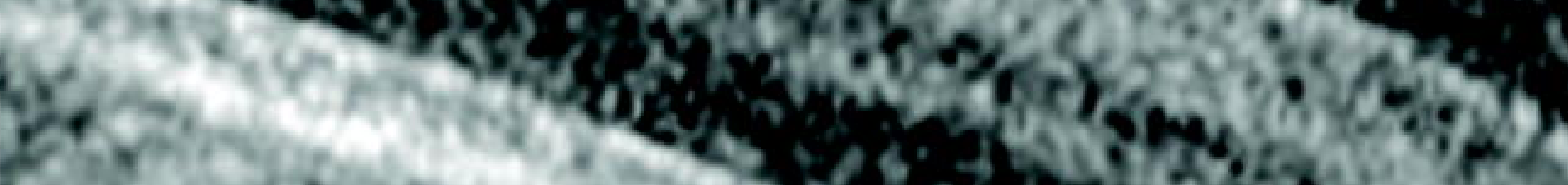

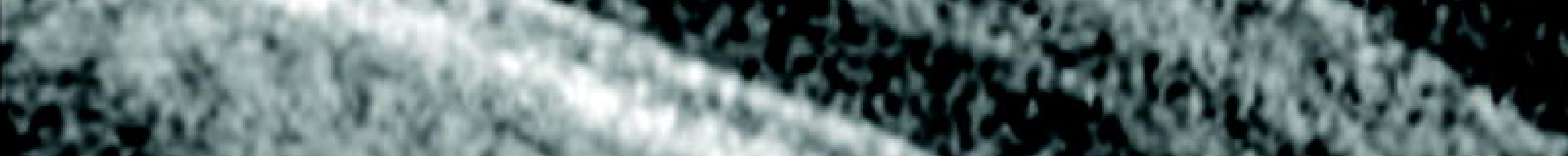

ST.

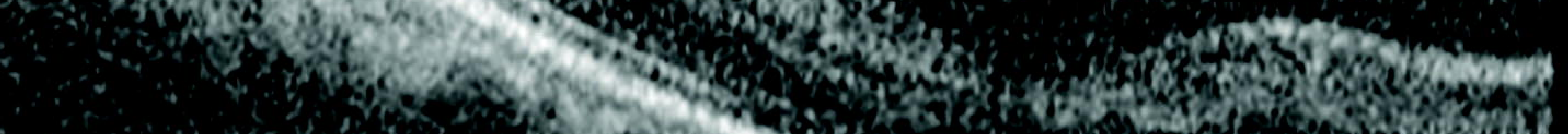

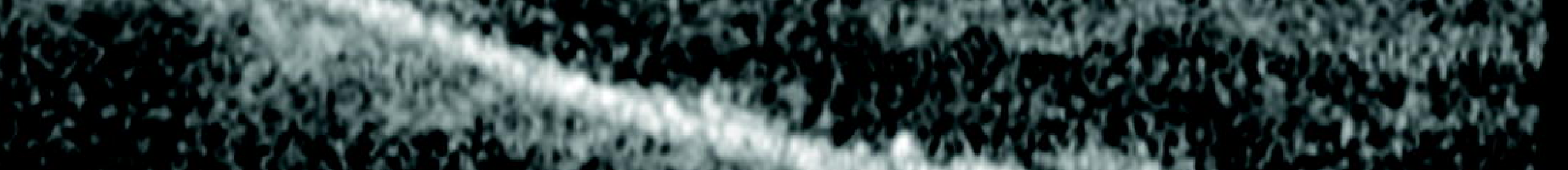

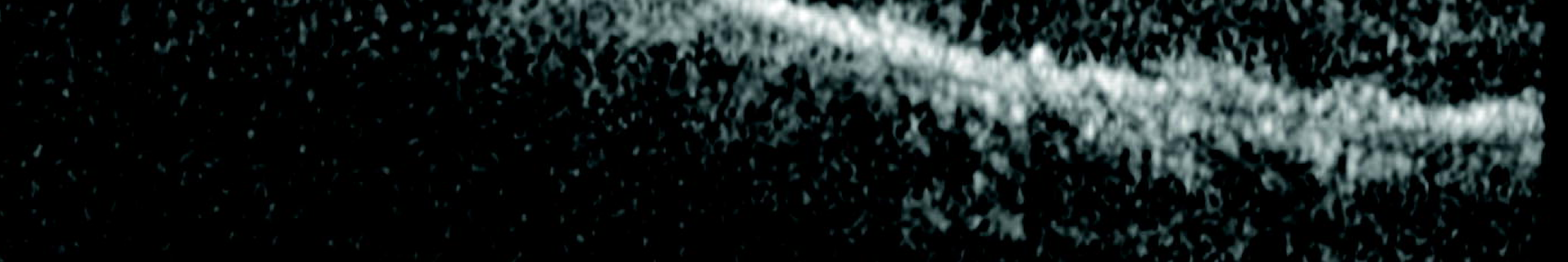
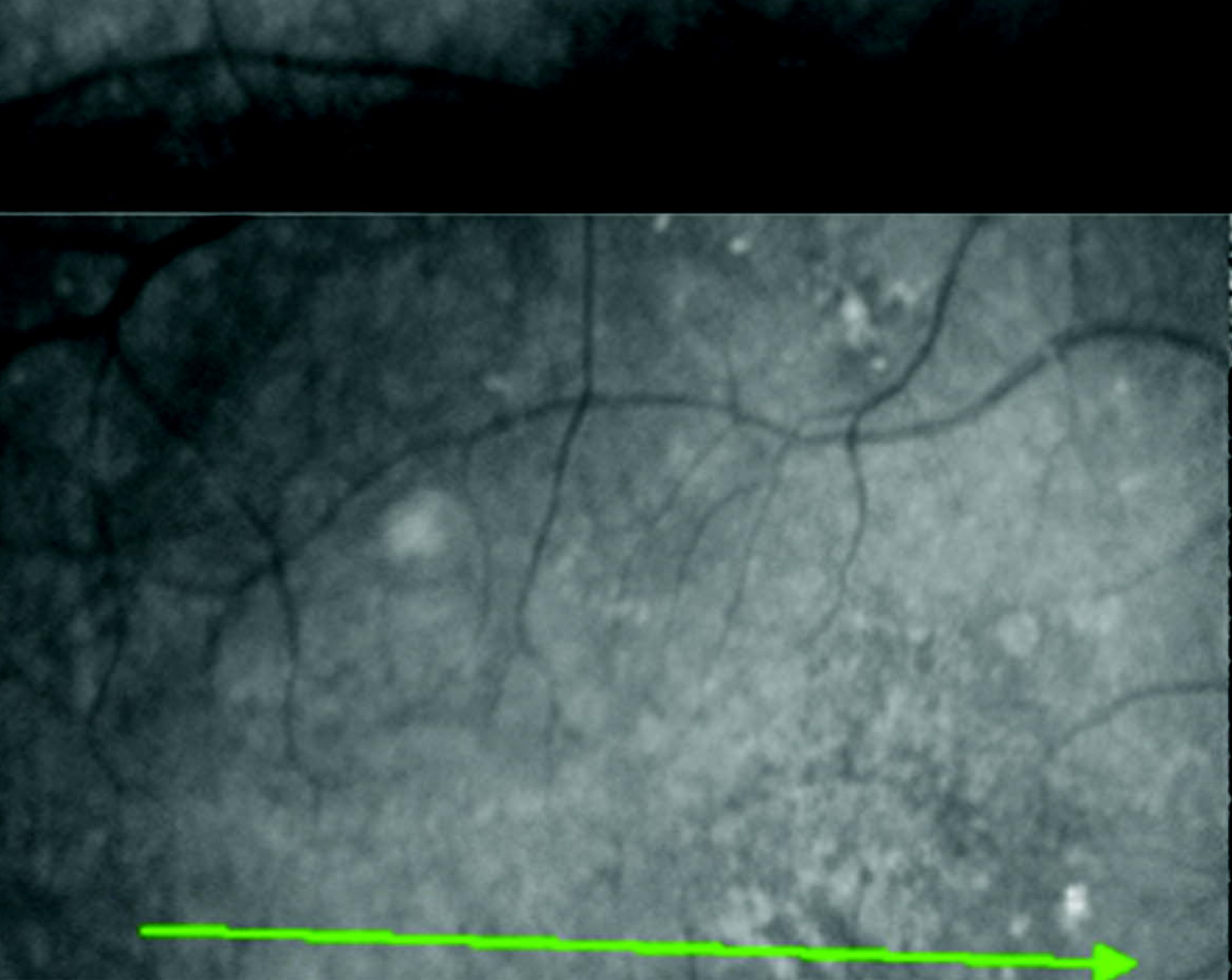

$200 \mu \mathrm{m}$

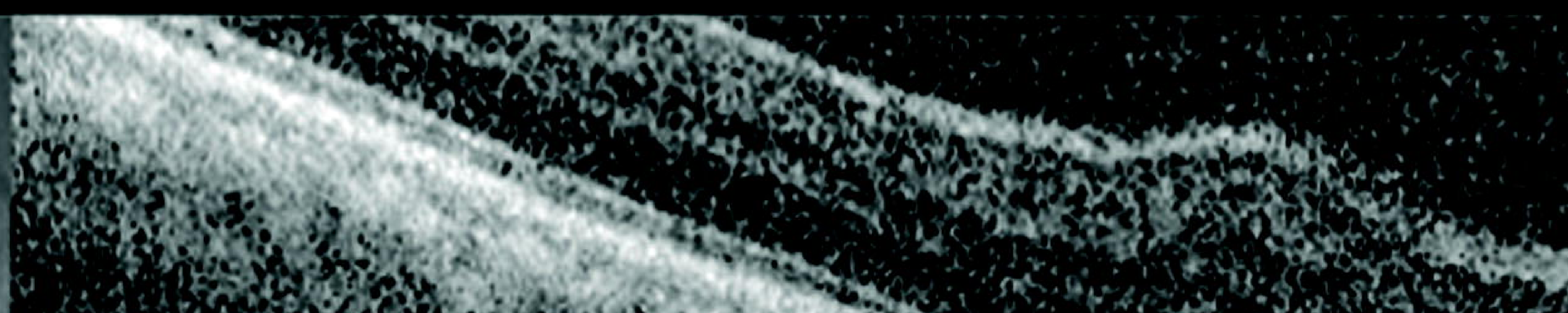

1.
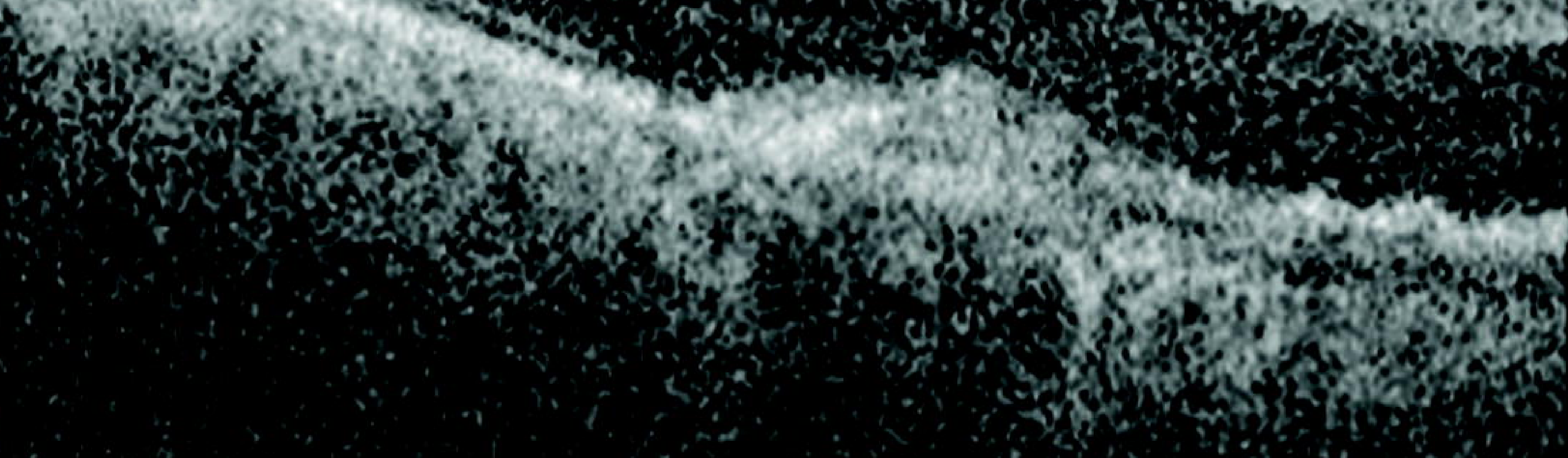

$E$ 


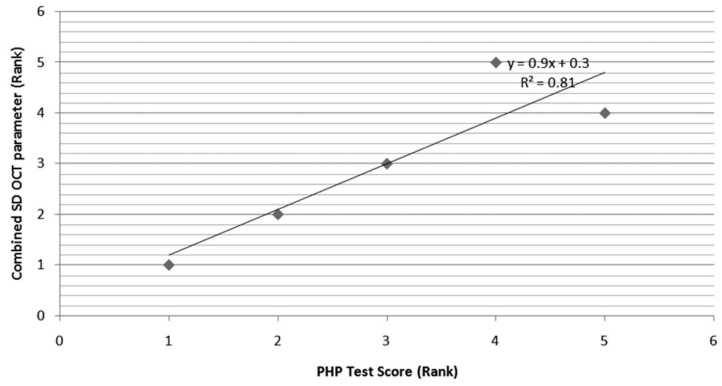




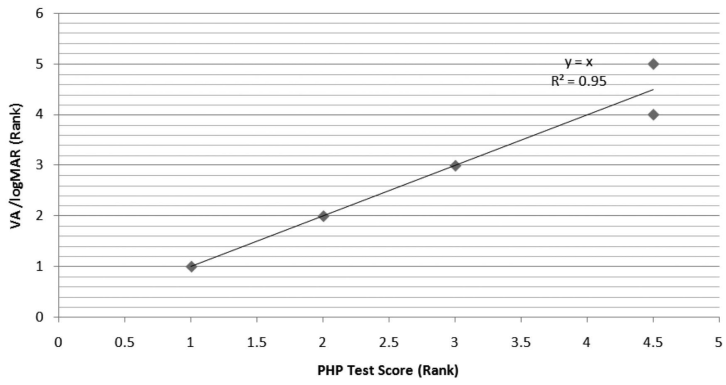




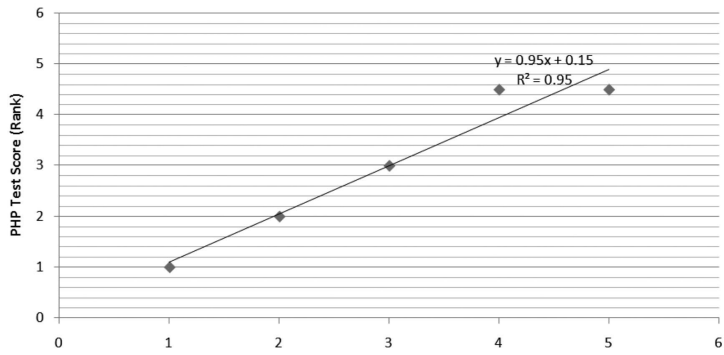

Combined SD OCT parameter (Rank) 